\title{
Serum Levels of Interleukin 6, a Potent Myeloma Cell Growth Factor, as a Reflect of Disease Severity in Plasma Cell Dyscrasias
}

\author{
Régis Bataille, ${ }^{\star *}$ Michel Jourdan, ${ }^{*}$ Xue-Guang Zhang, ${ }^{*}$ and Bernard Klein* \\ *Institut National de la Santé et de la Recherche Medicale U291, Zolad 34100 Montpellier Cédex, France; and ${ }^{\ddagger}$ Consultation \\ d'Immunorhumatologie, Centre Gui de Chauliac, Hôpital Saint-Eloi, 34059 Montpellier Cédex, France
}

\begin{abstract}
Using a specific and very sensitive (1 pg = $1 \mathrm{U}$ ) bioassay, we investigated the presence of IL-6, a potent myeloma cell growth factor, in the sera of 131 subjects with plasma cell dyscrasias. 22 had monoclonal gammopathy of undetermined significance (MGUS), 13 had smoldering myeloma (SMM), 85 had overt multiple myeloma (MM), and 11 had plasma cell leukemia (PCL). Significant serum IL-6 levels were detected in only 3\% of the MGUS/SMM group, but in 35\% of the overt MM group and $100 \%$ of the PCL group. During overt MM, IL-6 was detected in $37 \%$ of the patients at diagnosis, $13 \%$ of those with stable MM, and $60 \%$ of those with fulminating disease. These data demonstrate that serum levels of IL-6, a potent myeloma cell growth factor in vitro, correlate with disease severity in plasma cell dyscrasias. Serial studies performed in 3 patients and correlative studies with labeling index in vivo in 25 patients have confirmed this concept. Taken together, this suggests that this cytokine is probably involved in vivo during the progressive phase of MM. Thus, anti-IL-6 or anti-IL-6 receptor antibodies could be useful as therapeutic agents at this stage of the disease.
\end{abstract}

\section{Introduction}

IL-6, a pleiotropic cytokine with multiple biological activities (1), is a potent paracrine growth factor for hybridoma/plasmacytoma in mice $(2,3)$. Recently, this cytokine was found to be a strong in vitro myeloma cell growth factor in humans (4-6). However, its presentation as an autocrine (4) or paracrine (5, 6) growth factor remains controversial. Our recent studies have shown that this myeloma cell growth factor is overproduced in vitro in the bone marrow of patients with active multiple myeloma (MM; 6). ${ }^{1}$ Furthermore, we have recently

Address correspondence to Dr. Régis Bataille, Immunorhumatologie, Centre Gui de Chauliac, Hôpital Saint-Eloi, 34059 Montpellier Cédex, France.

Received for publication 21 February 1989 and in revised from 25 July 1989.

1. Abbreviations used in this paper: $\mathrm{CSF}$, colony-stimulating factor; $\mathrm{LI}$, labeling index; $\beta 2 \mathrm{~m}, \beta 2$ microglobulin; MGUS, monoclonal gammopathy of undetermined significance; MM, multiple myeloma; PCL, plasma cell leukemia; SMM, smoldering myeloma.

J. Clin. Invest.

(c) The American Society for Clinical Investigation, Inc 0021-9738/89/12/2008/04 \$2.00

Volume 84, December 1989, 2008-2011 found that IL-6 responsiveness of myeloma cells in vitro is directly correlated with their proliferative status in vivo (i.e., a high IL-6 responsiveness of myeloma cells in vitro is found in patients with proliferating myeloma cells in vivo and vice versa; 7). These data suggest that IL-6 might be involved in myeloma cell growth in vitro and in vivo. Interestingly, IL-6 can circulate and is detected in the serum and urine of renal transplant recipients (8), in the cerebrospinal fluid of patients with acute infection of the central nervous system (9), and in the synovial fluid and serum of patients with rheumatoid arthritis $(10,11)$. In this last disease serum IL-6 levels are a reliable reflect of disease activity (10). All these data prompted us to investigate the presence of IL-6 in the sera of subjects with monoclonal gammopathy of undetermined significance (MGUS), smoldering multiple myeloma (SMM), overt MM, and plasma cell leukemia (PCL). Our results clearly indicate that serum levels of IL-6 reflect disease severity in plasma cell dyscrasias. IL-6 was undetectable in most of the subjects with MGUS, SMM, and stable MM, whereas significant levels were indeed detected in $60 \%$ of those with fulminating $\mathrm{MM}$ and $100 \%$ of those with PCL. Thus, these data are in agreement with our previous work showing high IL-6 production in short-term cultures of bone marrow cells from patients with fulminating MM (6) and strongly suggest that IL-6 could be an important myeloma cell growth factor during the progressive phase of MM.

\section{Methods}

\section{Patients}

IL-6 was measured in the sera of 22 subjects with MGUS, 13 with SMM, 85 with overt MM, and 11 with PCL. MGUS, SMM, and overt MM were defined as previously reported (12). 48 patients with overt MM (previously untreated) were studied at diagnosis. According to Durie and Salmon's clinical staging (13), 58\% of the previously untreated patients had stage III MM. Patients with stable disease $(n=22)$ were in partial or complete remission and in the plateau phase (14). Patients with fulminating MM $(n=15)$ were undergoing a relapse or had progressive disease due to primary treatment failure (14). The 11 patients with PCL fulfilled the diagnostic criteria of MM and had $>20 \%$ plasma cells in the peripheral blood. Three patients had primary PCL and eight had secondary PCL. These patients were analyzed as a special group. None of the subjects showed overt inflammatory or infectious processes at the time of the study.

\section{Methods}

$I L-6$ bioassay. The sera were decomplemented for $30 \mathrm{~min}$ at $56^{\circ} \mathrm{C}$ and filtered before use. IL- 6 was assayed using the B9 IL-6-dependent hybridoma as previously reported $(6,15)$. Briefly, 5,000 B9 cells were cultured with serial dilutions of the sera $(1: 5$ to $1: 1,000)$. $4 \mathrm{~d}$ later 
proliferation was assayed by $\left[{ }^{3} \mathrm{H}\right]$ thymidine incorporation (6). The activity is expressed in units per milliliter, defined as the inverse of the dilution giving half-maximal proliferation. $1 \mathrm{U}$ corresponds to $\sim 1 \mathrm{pg}$ of IL-6 $(4,15)$. Only IL-6 activities higher than or equal to $5 \mathrm{U} / \mathrm{ml}$ (half-maximal proliferation of B9 cells at a serum dilution of 1:5) were taken into consideration. Lower IL- 6 activities were in fact difficult to estimate as some sera were found to suppress B9 cell proliferation at a dilution of 1:2. Such a difficulty in estimating low IL-6 levels in sera from healthy subjects or patients with various diseases was previously reported (10). It could be due either to specific inhibitors of IL-6 or to nonspecific inhibitors like serum complement components, known to inhibit various proliferative assays (16).

Inhibition of IL-6 activity by anti-IL-6 antibodies. Sera were diluted to a level yielding $2 \mathrm{U} / \mathrm{ml}$ of B9-proliferative activity. They were incubated for $2 \mathrm{~h}$ at room temperature with graded concentrations of a rabbit polyclonal antiserum to recombinant human IL-6 and their IL-6 activity was assayed with the B9 cells. This antiserum (a generous gift from Dr. Content, Brussels, Belgium) neutralized 40,000 U IL-6/ ml. Normal rabbit serum was used as control.

Proliferation assay of myeloma cells. Freshly isolated bone marrow cells or PBMC were cultured for $1 \mathrm{~h}$ in culture medium containing fluorodeoxyuridine $(10 \mathrm{mM})$ and bromodeoxyuridine $(100 \mathrm{mM})$. The percentage of myeloma cells in the $S$ phase were then determined using an antibromodeoxyuridine $\mathrm{MAb}$ (Bu-1; a generous gift from N. Gonchoroff, Mayo Clinic, Rochester, MI) and a rhodamine-labeled goat anti-mouse Ig (Cappel Laboratories, Cochranville, PA) in a double fluorescence technique previously described (17).

Statistical analysis. For statistical analysis we used the chi-square method with the Yates correction as necessary.

\section{Results and Discussion}

Growth factor activity for the B9 hybridoma was detected in 42 of 131 sera $(32 \%)$ from subjects with plasma cell dyscrasias (Fig. 1 and Table I). In 10 randomly selected sera with high hybridoma growth factor activity this activity was identified as IL- 6 because it was inhibited in a dose-dependent manner by

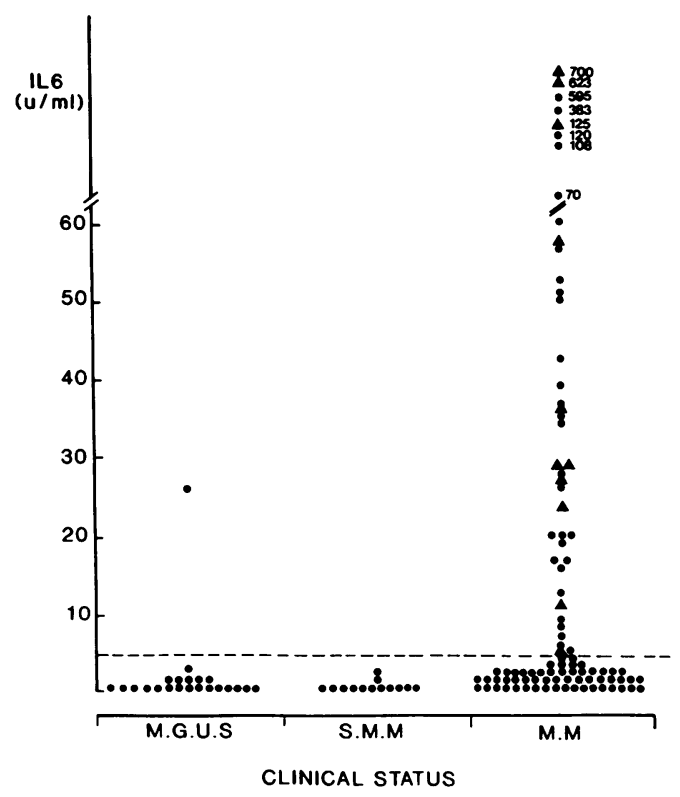

Figure 1. Serum IL-6 levels in patients with plasma cell dyscrasias. IL-6 activity was determined in serum from patients with MGUS ( $n$ $=22)$, SMM $(n=13)$, overt MM $(n=96)$, including 11 PCL represented by triangles. IL- 6 activity was determined using the B9-heterohybridoma proliferation assay.
Table I. Serum Levels of IL-6 in Plasma Cell Dyscrasias

\begin{tabular}{lcc}
\hline \multicolumn{1}{c}{ Clinical status } & $\begin{array}{c}\text { Serum IL-6 levels } \\
\geq 5 \mathrm{U} / \mathrm{ml}\end{array}$ & Statistical significance \\
\hline & $\%$ & \\
MGUS $(n=22)$ & & \\
and SM $(n=13)$ & 3 & $P<0.0005$ \\
Overt MM $(n=85)$ & 35 & $P<0.05$ \\
PCL $(n=11)$ & 100 & \\
\hline
\end{tabular}

specific anti-IL-6 antibodies. Two typical experiments are outlined in Fig. 2. Moreover, the B9 hybridoma used for testing IL-6 has been shown to respond only to IL-6. Specifically, it does not respond to human IL- $1 \alpha$ or $-\beta$, IL-2, IL-3, IL-4, tumor necrosis factor- $\alpha$ or granulocyte/macrophage colonystimulating factor (CSF) granulocyte CSF, CSF-1, acidic or basic fibroblast growth factors, or IFN- $\alpha,-\beta$, or $-\gamma(15$, and Klein, B., unpublished results).

Among the 22 subjects with MGUS, only one had detectable serum IL-6 (26 U/ml; Fig. 1). Interestingly, this was the only one to develop MM, 2 yr after serum sampling. None of the 13 patients with SMM showed detectable serum IL-6 (Fig. 1). Three of these patients subsequently developed overt MM. $35 \%$ (30 of 85 ) of the sera from patients with overt MM contained IL-6. This frequency was 11 times higher than that of the pooled group of subjects with MGUS and SMM (35 vs. 3\%, $P<0.0005$; Fig. 1 and Table I). It should be noted that all of the 11 patients with PCL, the most agressive form of malignant plasma cell dyscrasias, had large amounts of serum IL-6, one patient having as much as $700 \mathrm{U} / \mathrm{ml} \mathrm{IL-6} \mathrm{(Fig.} 1$ and Table I). High levels of IL-6 were detected in both primary and secondary PCL. A relationship between serum IL-6 and disease activity was clearly demonstrated in patients with overt MM (Fig. 3); indeed, the proportion of patients with detectable serum IL-6 was significantly higher at diagnosis (37\%) or during fulminating progression $(60 \%)$ than during the stable phase of the disease $(13 \% ; P$ at least $<0.05)$. Furthermore, in newly diagnosed patients with overt MM there was a trend $(P<0.1)$ towards increased serum IL-6 levels in those with high tumor

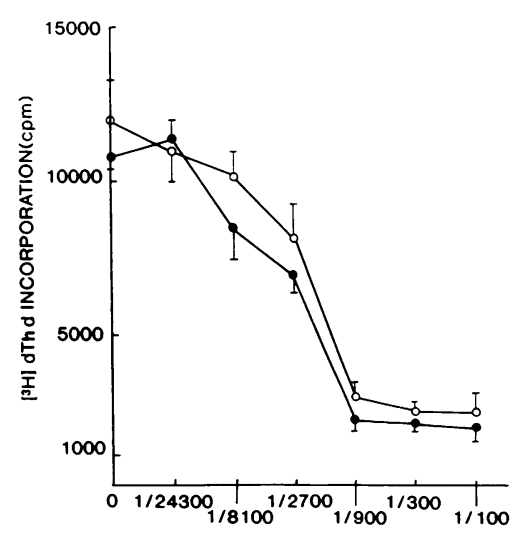

DILUTIONS OF ANTI-IL-6 ANTIBODY
Figure 2. Inhibition by anti-IL-6 antibodies of hybridoma growth factor activity present in the sera of patients with plasma cell dyscrasias. Sera were diluted to a concentration yielding 2 $\mathrm{U} / \mathrm{ml}$ of $\mathrm{B} 9$ proliferative activity. They were incubated for $2 \mathrm{~h}$ with graded concentrations of a rabbit polyclonal antiserum to recombinant human IL-6 and assayed for the B9 heterohybridoma proliferative activity. The antiserum to human IL-6 neutralized 40,000 U IL-6/ml. Results are mean values \pm SD of tritiated thymidine incorporation of quadruplate cultures. Inhibition experiments for two different sera initially containing 14 and $51 \mathrm{U} / \mathrm{ml}$ are represented. 


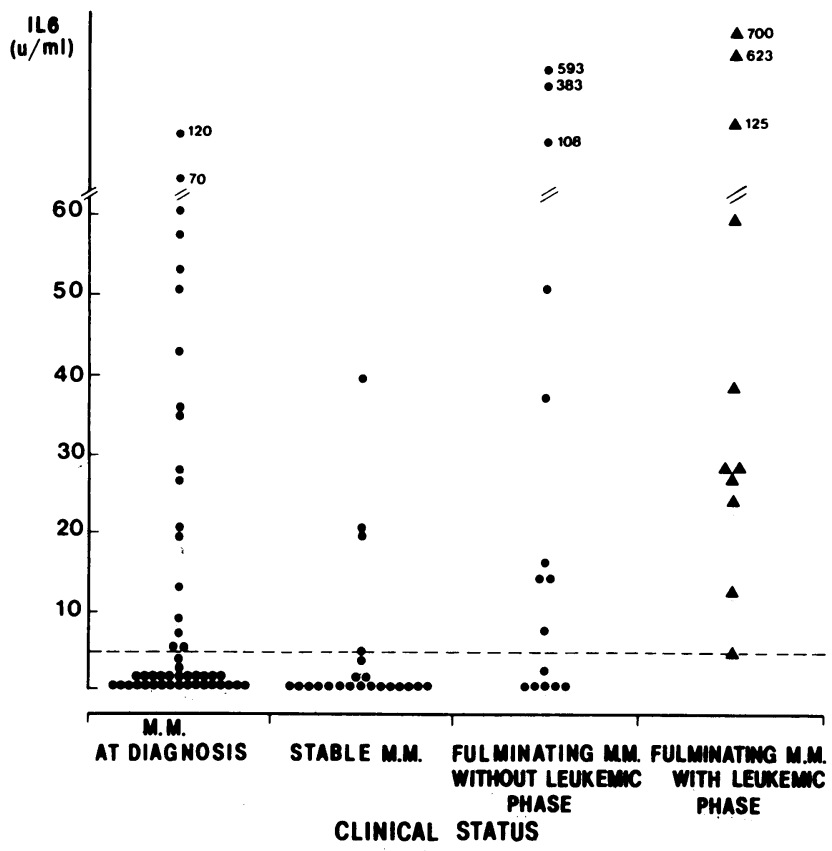

Figure 3. Relationship of serum IL-6 levels with disease activity in 96 patients with MM. Data from 11 patients with PCL (triangles) were classified as a group of fulminating $\mathrm{MM}$ with leukemic phase.

cell mass (i.e., stage III; 13$)$ or in those with high serum $\beta 2$ microglobulin $(\beta 2 \mathrm{~m})$ levels (i.e., $\beta 2 \mathrm{~m}>6 \mathrm{mg} /$ liter; 12 , Table II). However, when serum $\beta 2 \mathrm{~m}$ was analyzed in the overall population of patients with overt $\mathrm{MM}(n=87$ available out of 96), a more significant link was observed (Table II). Finally, serum IL-6 appeared more related to myeloma cell kinetics in vivo than to direct myeloma cell mass or to serum parameters reflecting myeloma cell mass such as $\beta 2 \mathrm{~m}$. Indeed, although no direct correlation was found between serum IL-6 levels and labeling index (LI; Fig. 4), a clear link exists between both parameters: IL- 6 was undetectable in the sera of all 10 patients with overt MM presenting a low $\mathrm{LI}$ in vivo (i.e., $\mathrm{LI}<1 \%$ ) even in the cases with high cell mass; on the other hand, IL- 6 was detected in 9 of 15 patients with overt MM or PCL and high LI

Table II. Relationship of Serum Levels of IL-6 with Parameters of Disease Activity in Patients with Overt MM

\begin{tabular}{lcc}
\hline \multicolumn{1}{c}{ Parameters } & $\begin{array}{c}\text { Serum IL-6 levels } \\
25 \mathrm{U} / \mathrm{ml}\end{array}$ & Statistical significance \\
\hline & $\%$ & \\
$\begin{array}{l}\text { Staging* } \\
\text { I + II }\end{array}$ & & $P<0.1$ \\
III $(n=29)$ & 21 & \\
$\beta 2 \mathrm{~m}(\text { mg/liter })^{\ddagger}$ & 48 & $P<0.01$ \\
$<6(n=52)$ & & \\
$>6(n=35)$ & 23 & $P<0.01$ \\
LI $\quad 77$ & \\
$<1 \%(n=10)$ & 0 & \\
$>1 \%(n=15)$ & 60 &
\end{tabular}

* According to Durie and Salmon for newly diagnosed patients with overt MM (13).

${ }^{\ddagger}$ Unavailable in 9 of 96 patients with overt MM.

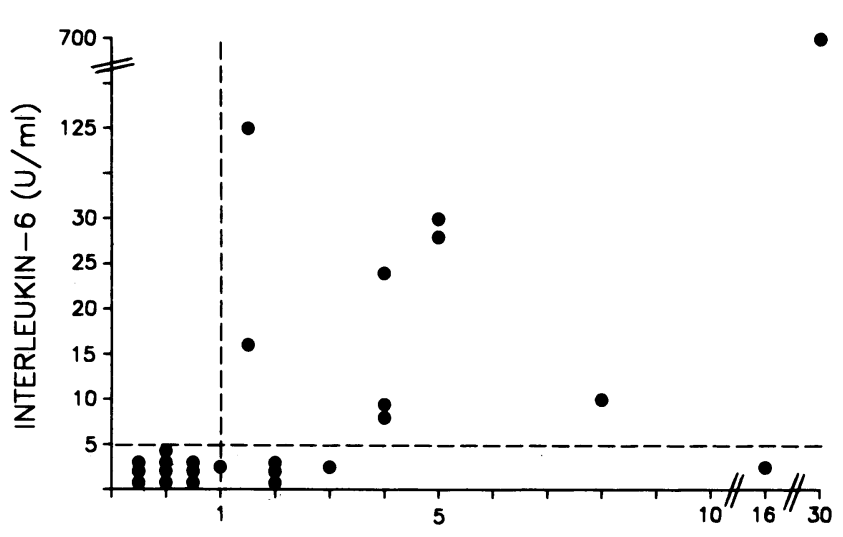

\% OF MYELOMA CELLS IN THE S PHASE

Figure 4. Relationship of serum IL-6 levels with in vivo kinetics (i.e., LI) of myeloma cells.

in vivo (i.e., $\mathrm{LI} \geq 1 \%, P<0.01$; Fig. 4 and Table II). The relationship between serum IL-6 levels and disease severity was also clearly demonstrated by serial studies performed in three patients. In all cases, disease progression within a few weeks or months from a nonleukemic phase to a terminal leukemic phase was associated with a significant increase in serum IL-6 levels, respectively, from 16 to $27 \mathrm{U} / \mathrm{ml}$ in patient 1,0 to 29 in patient 2 , and 10 to 700 in patient 3 .

We have recently shown that larger amounts of IL-6 are produced in short-term cultures of bone marrow cells from patients with active $M M$ than in those from patients with inactive disease or from healthy donors (6). The present results indicate that this increased IL-6 production in vitro reflects increased IL-6 production in vivo. As we and others have shown that IL-6 is a potent myeloma cell growth factor in vitro (4-6), it is crucial to identify which cells produce IL-6 in vivo. Kawano et al. (4) recently proposed that IL-6 is produced constitutively by myeloma cells and thus is an autocrine myeloma cell growth factor. However, since IL- 6 can be produced by many cell lineages (1), we consider that this point requires further confirmation using in situ hybridization and immunostaining with anti-IL-6 antibodies. Furthermore, the recent obtaining of IL-6-dependent human myeloma cell lines favors the paracrine hypothesis $(5$, and Klein, B., unpublished results). Whatever the mechanism, paracrine or autocrine, it is clear that IL-6 is a potent myeloma cell growth factor in vitro (4-6), mainly in patients with fulminating $M M$ and proliferating myeloma cells in vivo (7). The present data showing that serum IL-6 levels are significantly increased in patients with fulminating MM and in those with PCL strongly suggest that IL-6 is an important factor for the progression of MM in vivo. Thus, as suggested by Kawano et al. (4), anti-IL-6 therapeutics (anti-IL-6 antibodies, anti-IL-6 receptor antibodies, or IL-6 linked to a toxin) may be useful in treating patients with fulminating MM, especially those with PCL.

\section{Acknowledgments}

We with to thank Mrs. L. Bataille-Zagury for editing the English text, and Dr. N. Gonchoroff and Dr. Ph. Greipp (Mayo Clinic, Rochester, $\mathrm{MN}$ ) for providing us with the antibromodeoxyuridine MAb.

This work was supported by grants from l'Association pour la Recherche sur le Cancer and la Ligue Nationale Française contre le Cancer, Paris, France. 


\section{References}

1. Wong, G. G., and S. C. Clark. 1988. Multiple actions of interleukin 6 within a cytokine network. Immunol. Today. 9:137-139.

2. Aarden, L. A., E. R. De Groot, O. L. Shaap, and P. M. Lansdorp. 1987. Production of hybridoma growth factor by human monocytes. Eur. J. Immunol. 17:1411-1416.

3. Van Damme, J., G. Opdenakker, R. J. Simpson, M. R. Rubira, S. Cayphas, A. Vink, A. Billiau, and J. Van Snick. 1987. Identification of the human $26-\mathrm{kD}$ protein, interferon $\beta 2$ (IFN- $\beta 2$ ) as a B cell hybridoma/plasmacytoma growth factor induced by interleukin 1 and tumor necrosis factor. J. Exp. Med. 165:914-920.

4. Kawano, M., T. Hirano, T. Matsuda, T. Taga, Y. Horii, K. Iwato, H. Asaoku, B. Tang, O. Tanabe, H. Tanaka, A. Kuramoto, and T. Kishimoto. 1988. Autocrine generation and essential requirement of BSF-2/IL-6 for human multiple myeloma. Nature (Lond.). 322:8386.

5. Shimizu, S., R. Yoshioka, Y. Hirose, S. Sugai, J. Tachibana, and S. Konda. 1989. Establishment of two interleukin-6 (B-cell stimulatory factor 2 /interferon- $\beta 2$ ) dependent human bone marrow derived myeloma cell lines. J. Exp. Med. 169:339-344.

6. Klein, B., X. G. Zhang, M. Jourdan, J. Content, F. Houssiau, L. Aarden, M. Piechaczyck, and R. Bataille. 1989. A paracrine rather than autocrine regulation of myeloma cell growth and differentiation by interleukin-6. Blood. 73:517-526.

7. Zhang, X. G., B. Klein, and R. Bataille. 1989. Interleukin-6 is a potent myeloma-cell growth factor in patients with agressive multiple myeloma. Blood. 74:11-13.

8. Van Oers, M. H. J., Van der Heyden A., and L. A. Aarden. 1988. Interleukin-6 (IL-6) in serum and urine of renal transplant recipients. Clin. Exp. Immunol. 71:314-319.
9. Houssiau, F. A., K. Busaka, C. J. M. Sindic, J. Van Damme, and J. Van Snick. 1988. Elevated levels of the $26 \mathrm{~K}$ human hybridoma growth factor (interleukin-6) in cerebrospinal fluid of patients with acute infection of the central nervous system. Clin. Exp. Immunol. 71:320-323.

10. Houssiau, F. A., J. P. Devogelaer, J. Van Damme, C. Nagant de Deuxchaisnes, and J. Van Snick. 1988. Interleukin-6 in synovial fluid and serum of patients with rheumatoid arthritis and other inflammatory arthritides. Arthritis Rheum. 31:784-788.

11. Hirano, T., T. Matsuda, M. Turner, N. Miyasaka, G. Buchan, B. Tang, K. Sato, M. Shimizu, R. Maini, M. Feldman, and T. Kishimoto. 1988. Excessive production of interleukin-6/B-cell stimulatory factor-2 in rheumatoid arthritis. Eur. J. Immunol. 18:1797-1801.

12. Durie, B. G. M. 1986. Staging and kinetics of multiple myeloma. Semin. Oncol. 13:300-309.

13. Durie, B. G. M., and S. E. Salmon. 1975. A clinical staging system for multiple myeloma. Cancer (Phila.). 36:842-854.

14. Bataille, R., P. Souteyrand, and J. Sany. 1984. Clinical evaluation of response or escape to chemotherapy and of survival of patients with multiple myeloma: a prospective study of 202 patients (19751982). Anticancer Res. 4:339-346.

15. Helle, M., L. Boeise, and L. A. Aarden. 1988. Functional discrimination between interleukin-6 and interleukin-1 Eur. J. Immunol. 18:1535-1540.

16. Pruett, S. B., and A. Lackey. 1987. Apparent interleukin-2 (IL-2) inhibitory activity of human serum is due to rapid killing of IL-2 dependent mouse cells. Clin. Exp. Immunol. 69:624-634.

17. Gonchoroff, N. J., P. R. Greipp, R. A. Kyle, and J. A. Katzmann. 1985. A monoclonal antibody reactive with 5-Bromo-2-deoxyuridine that does not require DNA denaturation. Cytometry. 6:506512. 